\title{
EEG theta/beta ratio as an electrophysiological marker for attentional control and its test-retest reliability
}

\author{
Angelos Angelidis ${ }^{\mathrm{a}, \mathrm{b}}$, Willem van der Does ${ }^{\mathrm{a}, \mathrm{b}}$, Lemmy Schakel $^{\mathrm{a}, \mathrm{b}}$, Peter Putman ${ }^{\mathrm{a}, \mathrm{b}}$

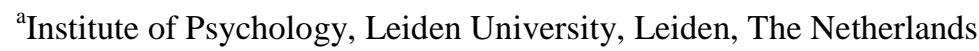 \\ ${ }^{\mathrm{b}}$ Leiden Institute for Brain and Cognition, Leiden, The Netherlands
}

\begin{abstract}
A robust finding is that resting-state frontal theta/beta ratio (TBR), a spontaneous electroencephalographic (EEG) frequency band parameter, is increased in attentiondeficit/hyperactivity disorder. Accumulating evidence suggests that TBR might also provide an objective marker of executive cognitive control (and more specifically attentional control; AC) in healthy adults. The present study aimed to further investigate this conception by assessing EEG frequency band power and AC twice (with a one-week interval) in 41 young female adults. In line with our predictions, the negative association between TBR and trait $\mathrm{AC}$, as measured with an often used self-report measure, was replicated. Results also demonstrated that test-retest reliability of resting-state frontal TBR was very good $(r=.93)$ and, moreover, TBR measured at the first session predicted AC during the second session $(r=$ -.44). These consistent results further reinforce the notion that frontal TBR could be used as a reliable biomarker for prefrontally-mediated executive AC.
\end{abstract}

Keywords: EEG, Theta/beta ratio, Attentional control, Test-retest reliability

Corresponding author: Angelos Angelidis, Clinical Psychology, Leiden University, Wassenaarseweg 52, PO Box 9555, 2300 RB, Leiden, The Netherlands.

Tel.: +31715276457

e-mail address: a.angelidis@fsw.leidenuniv.nl

Acknowledgements

PP is supported by a grant from the Netherlands Organization for Scientific Research (NWO; \#452-

12-003. NWO was not involved in any part of the current study. 
There is increasing interest in slow wave/fast wave (sw/fw) spectrum measures for spontaneous electroencephalography (EEG) in relation to individual differences in cognitive control and emotional processing (Knyazev, 2007; Massar et al., 2014; Putman et al., 2014; Sari et al., 2015; Schutter and Knyazev, 2012; Tortella-Feliu et al., 2014). Spontaneous theta/beta ratio (TBR), the ratio of theta band $(4-7 \mathrm{~Hz})$ power divided by beta band $(13-30 \mathrm{~Hz})$ power, is argued to reflect cortical-subcortical interactions (Arns et al., 2013; Schutter and Van Honk, 2005) and accumulating evidence indicates that it might be a promising biomarker for prefrontally mediated executive control functions, most notably attentional control (AC).

AC is suggested to be regulated by two reciprocal systems; a bottom-up system, instigating the detection and engagement of salient stimuli, which is carried out by anterior cingulate cortex (ACC) and subcortical areas such as the thalamus and amygdala (Bishop, 2008; Hermans et al., 2014), and an intentional top-down system, responsible for maintaining attention to task-relevant information mediated importantly by (dorso-) lateral prefrontal cortex (dlPFC; Bishop, 2008; Fani et al., 2012; Gregoriou et al., 2014). Numerous studies have demonstrated that TBR is elevated in attention deficit/hyperactivity disorder (ADHD) and in the predominantly inattentive subtype of attention deficit disorder (ADD; Arns et al., 2013). In addition, psychostimulants which increase PFC network integrity normalize TBR and reduce ADHD symptoms (Arnsten, 2006; Clarke et al., 2002; Clarke et al., 2007). Since ADHD symptoms likely stem from (frontal) cortical hypoarousal and subcortical hyperarousal (Barry et al., 2003; Lubar, 1991), the ADHD-TBR literature strongly supports the idea that TBR might reflect frontal cortical regulation of subcortical processes. Recent years have seen an increasing interest in TBR in healthy adults. Studies have reported, for instance, a negative relationship between TBR and trait AC as well as stress-induced AC decline (Putman et al., 2010; 2014), attentional orienting (Morillas-Romero et al., 2015b), emotion regulation (Tortella-Feliu et al., 2014), behavioral inhibition (Putman et al., 2010) 
and motivated decision making (Massar et al., 2014; Massar et al., 2012), all in healthy adults.

In the present study, we aimed to replicate the cross-sectional negative relationship between frontal TBR and self-reported AC (hypothesis 1). Moreover, to further explore the potential usefulness of TBR as a biomarker for prefrontal executive control function we measured TBR and AC in two separate sessions, separated by one week, allowing the first assessment of TBR's test-retest reliability (hypothesis 2) and its ability to predict AC (hypothesis 3). We also included measures of trait anxiety to control for possible confounding relationships (c.f. Putman et al., 2010; 2014).

\section{Methods}

\section{Participants}

Forty-one healthy female participants (for practical reasons) from Leiden University campus were tested. Participants were screened for use of psychoactive medication, and written informed consent was obtained. After participation, two participants were excluded for use of psychoactive medication. Age ranged between 18 and $31(M=21.2, S D=2.9)$. Participation was compensated with course credits or a small monetary reward. The study was approved by the local review board.

\subsection{Materials}

\subsubsection{Self-report measures}

Trait anxiety was assessed with the trait version of Spielberger's State-Trait Anxiety Inventory (STAI-t; Spielberger, 1983; Van der Ploeg et al., 1980). The Attentional Control Scale (ACS; Derryberry and Reed, 2002; Verwoerd et al., 2006) was used to assess attentional control. 


\subsubsection{EEG recording and data reduction}

For a full description, see Putman et al. (2014). We analyzed the average area power densities of the frontal electrodes (Fz, F3, F4). Non-normally distributed power densities and TBR values were normalized (natural log transformed, Ln) before statistical hypothesis testing.

\subsection{Procedures}

Participants were invited to the same lab twice with an one-week interval. On both sessions, participants first completed the questionnaires, followed by the baseline EEG measurement.

\section{Results}

Table 1 and 2 provide descriptives, correlations, and t-tests comparing all the measurements between the two sessions, as well as the correlations between these measurements during both sessions, respectively.

\subsection{Data reduction}

One participant was excluded from analyses as an outlier (score more than $2.5 \mathrm{SD}$ above the group mean) for Ln-normalized beta power density during the first session. Next, Mahalanobis distance revealed a significant bivariate outlier for the relationship between TBR and $\operatorname{ACS}\left(D^{2}=11.20, p<.005\right)$ which was removed from relevant analyses (results were very similar for the original sample).

\subsection{Self-reported measures}

As commonly reported (e.g. Bishop et al., 2007; Derryberry and Reed, 2002; Putman et al., 2014), significant negative correlations were found between ACS and STAI-t. STAI-t scores did not differ between the two sessions but ACS were lower in the second session. Test-retest reliability of ACS and STAI-t were very high (see Table 1). 
Table 1

Means (and standard deviations) for self-report and frontal EEG data of both sessions $(n=38)$.

\begin{tabular}{llllll}
\hline & TBR & Theta power & Beta power & ACS & STAI-t \\
\hline Session 1 & $1.161(0.531)$ & $12.926(6.078)$ & $11.903(4.417)$ & $55.2(8.5)$ & $37.2(7.4)$ \\
Session 2 & $1.272(0.589)$ & $14.703(7.258)$ & $12.404(4.764)$ & $54.0(8.6)$ & $36.4(7.9)$ \\
$r$ & $.93 * * *$ & $.94 * * *$ & $.90^{* * *}$ & $.91^{* * *}$ & $.92^{* * *}$ \\
$t$ & $-3.22^{* *}$ & $-4.67 * * *$ & -1.14 & $2.18^{*}$ & 1.42 \\
$d$ & .52 & .76 & .19 & .35 & .23 \\
\hline
\end{tabular}

Note: reported descriptives of frontal TBR, theta power, and beta power are not Ln-normalized for more intuitive appreciation and comparability with other studies. ${ }^{*} p<.05,{ }^{*} p<.005$, ${ }^{* * *} p<.001$

\section{Table 2}

Pearson correlation coefficients between group characteristics during both sessions ( $n=38$ apart from the relationship between TBR and ACS where $n=37$ ).

\begin{tabular}{|c|c|c|c|c|c|c|c|}
\hline & \multirow[b]{2}{*}{ session } & \multicolumn{2}{|l|}{ TBR } & \multicolumn{2}{|l|}{ ACS } & \multicolumn{2}{|l|}{ STAI-t } \\
\hline & & 1 & 2 & 1 & 2 & 1 & 2 \\
\hline \multirow{2}{*}{ TBR } & 1 & - & & & & & \\
\hline & 2 & $.93 * * *$ & - & & & & \\
\hline \multirow{2}{*}{ ACS } & 1 & $-.47 * *$ & $-.44 * *$ & - & & & \\
\hline & 2 & $-.44 * *$ & $-.37 *$ & $.91 * * *$ & - & & \\
\hline \multirow{2}{*}{ STAI-t } & 1 & .11 & .07 & $-.57 * * *$ & $-.59 * * *$ & - & \\
\hline & 2 & .09 & .04 & $-.54 * * *$ & $-.62 * * *$ & $92 * * *$ & - \\
\hline
\end{tabular}

\subsection{TBR and $A C$}

Significant negative correlations were found between frontal TBR and ACS in both sessions. Moreover, TBR in both sessions correlated with ACS scores of contrasting sessions (see Table 2; Fig. 1). These correlations remained significant after controlling for STAI-t (weakest correlation $r<-.39, p=.02$; cf. Putman et al., 2010). 


\subsection{Test-retest reliability}

Test-retest reliability of TBR was very high $(r=.93)$ even though TBR was higher during the second session (Fig.1). Post-hoc t-tests suggest that the increase of TBR in the second session was due to increase of theta power (see Table 1).

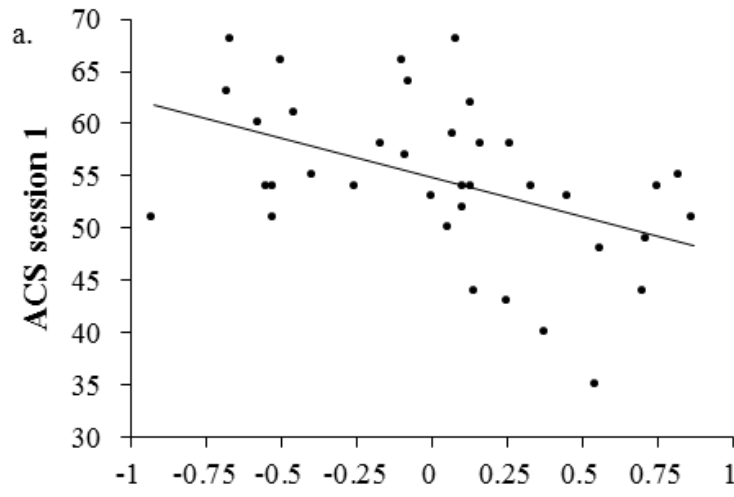

TBR session 1 (Ln)

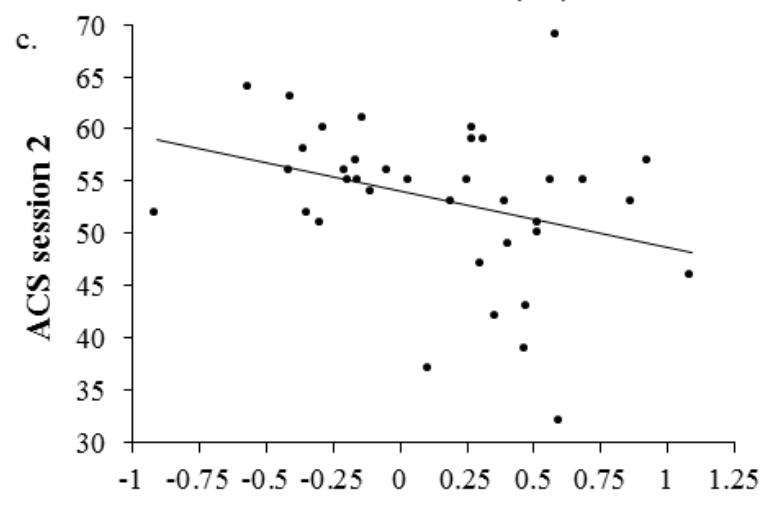

TBR session 2 (Ln)

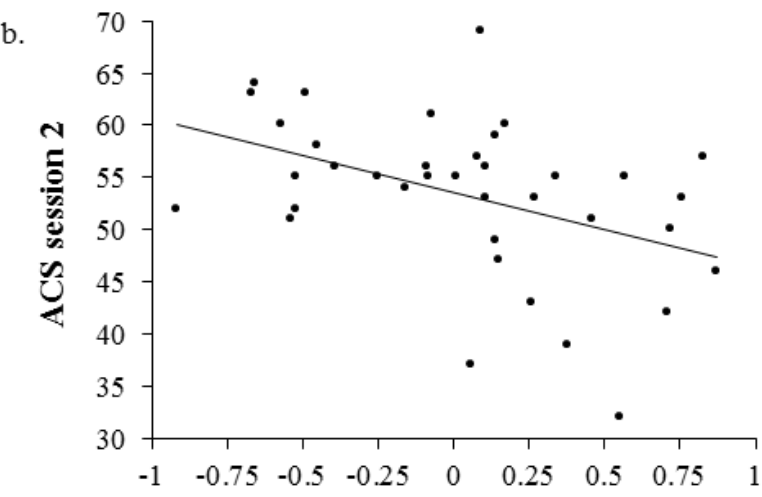

TBR session 1 (Ln)

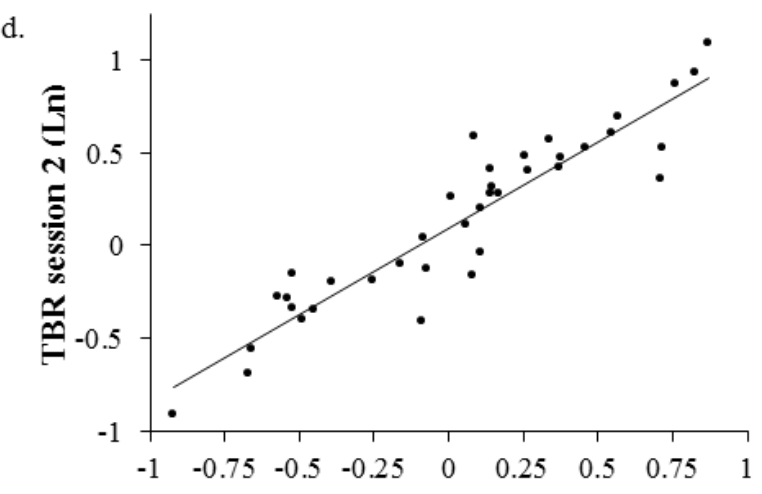

TBR session 1 (Ln)

Fig 1. Scatterplots for the relations between first-session frontal TBR and ACS ( $n=37)$ during the first session (panel a) and second session (b), frontal TBR and ACS during the second session (c), and the 2 sessions of frontal TBR $(\mathrm{d} ; n=38)$.

\subsection{Age}

Associations of age with TBR and ACS were also tested as they have been previously reported by Putman et al. (2010). Since log-normalized age was still not normally distributed, Spearman's correlations were conducted. A negative association between age and TBR $\left(r_{s}=-\right.$ $.40, p=.014 ; r_{s}=-.38, p=.02$, for the first and the second session respectively) was found.

There was no significant relation between age and ACS $\left(r_{s}=.04, p=.812 ; r_{s}=-.01, p=.949\right.$, 
for the two sessions). The negative relaitonship between TBR and ACS for both sessions remained significant after controlling for age (weakest correlation $r=-.41, p=.014$; c.f. Putman et al., 2010).

\section{Discussion}

The main goal of this study was to replicate the previously reported cross-sectional relationship between spontaneous frontal EEG TBR and trait AC, and further to assess the one-week test-retest reliability of frontal TBR and its prediction of AC. Consistent with previous research (Putman et al., 2010), a negative association was found between TBR and attentional control. This association was significant even when the measurements were conducted in different sessions. The one-week test-retest reliability of TBR was very high.

These findings are in line with previous studies (Putman et al., 2010; 2014) supporting the idea that TBR might indeed reflect capacity of AC in healthy individuals. Most research in TBR focused on $\mathrm{AD}(\mathrm{H}) \mathrm{D}$ patients whose main symptoms are attributed to difficulties with PFC attentional regulation. Recently, there is increasing evidence that frontal TBR associates with executive control functions also in healthy individuals. ACS is a self-report measure, of the executive capacity to focus or switch attention, that has often been associated with cognitive regulation over automatic processing of threat-related emotional stimuli (Bishop et al., 2007; Derryberry and Reed, 2002; Putman et al., 2012; Schoorl et al., 2014) and spontaneous emotional regulation of threatening information (Morillas-Romero et al., 2015a). Accordingly, it has been found that individuals with high TBR have difficulties in inhibiting emotional stimuli (Putman et al., 2010) or regulating their emotions (Tortella-Feliu et al., 2014). Neural models suggest that PFC-mediated AC is a key function in the processing of emotional information such as selective attention or cognitive reappraisal (Ochsner et al., 2012), processes that are disrupted in different types of psychopathology (Etkin and Wager, 
2007; Joormann and Gotlib, 2010) so TBR's ability to predict AC is a potentially very useful biomarker.

Test-retest reliability of TBR was very high despite the fact that TBR was increased during the second session. Although other EEG spectral power densities are found to be consistent over time during resting-state (e.g. Corsi-Cabrera et al., 2007), this is the first study to our knowledge investigating the test-retest reliability of spontaneous TBR. The unexpected increase of TBR during the second session (likely due to the increased theta power), might be attributed to participants' habituation (and their possibly more relaxed state; Lagopoulos et al., 2009) as the procedure and the context were identical to the first session. Regardless, testretest reliability of TBR and its prediction of ACS were very good and all in all, TBR seems to provide a reliable and trait-like marker of AC.

There was presently no evidence of an association between TBR and trait anxiety, which has been reported before (Putman et al., 2010). Further research should investigate the relation of spontaneous TBR with anxiety. In summary, these findings support the notion that frontal EEG TBR might be a stable and valuable biomarker for trait-like PFC-mediated executive control.

Reference list

Arns, M., Conners, C.K., Kraemer, H.C., 2013. A decade of EEG Theta/Beta Ratio Research in ADHD: a meta-analysis. J Atten Disord 17, 374-383.

Arnsten, A.F.T., 2006. Stimulants: Therapeutic actions in ADHD, Neuropsychopharmacol, pp. 23762383.

Barry, R.J., Clarke, A.R., Johnstone, S.J., 2003. A review of electrophysiology in attentiondeficit/hyperactivity disorder: I. Qualitative and quantitative electroencephalography. Clin Neurophysiol 114, 171-183.

Bishop, S.J., 2008. Neural mechanisms underlying selective attention to threat. Ann N Y Acad Sci $1129,141-152$.

Bishop, S.J., Jenkins, R., Lawrence, A.D., 2007. Neural processing of fearful faces: effects of anxiety are gated by perceptual capacity limitations. Cereb Cortex 17, 1595-1603. 
Clarke, A.R., Barry, R.J., McCarthy, R., Selikowitz, M., Brown, C.R., 2002. EEG evidence for a new conceptualisation of attention deficit hyperactivity disorder. Clin Neurophysiol 113, 10361044.

Clarke, A.R., Barry, R.J., McCarthy, R., Selikowitz, M., Johnstone, S.J., 2007. Effects of stimulant medications on the EEG of girls with Attention-Deficit/Hyperactivity Disorder. Clin Neurophysiol 118, 2700-2708.

Corsi-Cabrera, M., Galindo-Vilchis, L., del-Rio-Portilla, Y., Arce, C., Ramos-Loyo, J., 2007. Withinsubject reliability and inter-session stability of EEG power and coherent activity in women evaluated monthly over nine months. Clin Neurophysiol 118, 9-21.

Derryberry, D., Reed, M.A., 2002. Anxiety-related attentional biases and their regulation by attentional control. J Abnorm Psychol 111, 225-236.

Etkin, A., Wager, T.D., 2007. Functional neuroimaging of anxiety: a meta-analysis of emotional processing in PTSD, social anxiety disorder, and specific phobia. Am J Psychiatry 164, 14761488.

Fani, N., Jovanovic, T., Ely, T.D., Bradley, B., Gutman, D., Tone, E.B., Ressler, K.J., 2012. Neural correlates of attention bias to threat in post-traumatic stress disorder. Biol Psychol 90, 134142.

Gregoriou, G.G., Rossi, A.F., Ungerleider, L.G., Desimone, R., 2014. Lesions of prefrontal cortex reduce attentional modulation of neuronal responses and synchrony in V4. Nat Neurosci 17, 1003-1011.

Hermans, E.J., Henckens, M.J., Joels, M., Fernandez, G., 2014. Dynamic adaptation of large-scale brain networks in response to acute stressors. Trends Neurosci 37, 304-314.

Joormann, J., Gotlib, I.H., 2010. Emotion regulation in depression: relation to cognitive inhibition. Cogn Emot 24, 281-298.

Knyazev, G.G., 2007. Motivation, emotion, and their inhibitory control mirrored in brain oscillations. Neurosci Biobehav R 31, 377-395.

Lagopoulos, J., Xu, J., Rasmussen, I., Vik, A., Malhi, G.S., Eliassen, C.F., Arntsen, I.E., Saether, J.G., Hollup, S., Holen, A., Davanger, S., Ellingsen, O., 2009. Increased theta and alpha EEG activity during nondirective meditation. J Altern Complement Med 15, 1187-1192.

Lubar, J.F., 1991. Discourse on the development of EEG diagnostics and biofeedback for attentiondeficit/hyperactivity disorders. Biofeedback Self Regul 16, 201-225.

Massar, S.A., Kenemans, J.L., Schutter, D.J., 2014. Resting-state EEG theta activity and risk learning: sensitivity to reward or punishment? Int J Psychophysiol 91, 172-177.

Massar, S.A., Rossi, V., Schutter, D.J., Kenemans, J.L., 2012. Baseline EEG theta/beta ratio and punishment sensitivity as biomarkers for feedback-related negativity (FRN) and risk-taking. Clin Neurophysiol 123, 1958-1965.

Morillas-Romero, A., Tortella-Feliu, M., Balle, M., Bornas, X., 2015a. Spontaneous emotion regulation and attentional control. Emotion 15, 162-175.

Morillas-Romero, A., Tortella-Feliu, M., Bornas, X., Putman, P., 2015b. Spontaneous EEG theta/beta ratio and delta-beta coupling in relation to attentional network functioning and self-reported attentional control. Cogn Affect Behav Neurosci 15, 598-606.

Ochsner, K.N., Silvers, J.A., Buhle, J.T., 2012. Functional imaging studies of emotion regulation: a synthetic review and evolving model of the cognitive control of emotion. Ann N Y Acad Sci 1251, E1-24.

Putman, P., Arias-Garcia, E., Pantazi, I., van Schie, C., 2012. Emotional Stroop interference for threatening words is related to reduced EEG delta-beta coupling and low attentional control. International Journal of Psychophysiology 84, 194-200.

Putman, P., van Peer, J., Maimari, I., van der Werff, S., 2010. EEG theta/beta ratio in relation to fearmodulated response-inhibition, attentional control, and affective traits. Biol Psychol 83, 7378. 
Putman, P., Verkuil, B., Arias-Garcia, E., Pantazi, I., van Schie, C., 2014. EEG theta/beta ratio as a potential biomarker for attentional control and resilience against deleterious effects of stress on attention. Cogn Affect Behav Ne 14, 782-791.

Sari, B.A., Koster, E.H., Pourtois, G., Derakshan, N., 2015. Training working memory to improve attentional control in anxiety: A proof-of-principle study using behavioral and electrophysiological measures. Biol Psychol.

Schoorl, M., Putman, P., Van Der Werff, S., Van Der Does, A.J., 2014. Attentional bias and attentional control in Posttraumatic Stress Disorder. J Anxiety Disord 28, 203-210.

Schutter, D.J., Knyazev, G.G., 2012. Cross-frequency coupling of brain oscillations in studying motivation and emotion. Motiv Emot 36, 46-54.

Schutter, D.J.L.G., Van Honk, J., 2005. Electrophysiological ratio markers for the balance between reward and punishment. Cognitive Brain Res 24, 685-690.

Spielberger, C.D., 1983. Manual for the State-Trait Anxiety Inventory (STAI form Y). Consulting Psychologists Press, Palo Alto.

Tortella-Feliu, M., Morillas-Romero, A., Balle, M., Llabres, J., Bornas, X., Putman, P., 2014. Spontaneous EEG activity and spontaneous emotion regulation. Int J Psychophysiol 94, 365372.

Van der Ploeg, H.M., Defares, P.B., Spielberger, C.D., 1980. ZBV: Handleiding bij de zelf-beoordelings vragenlijst: Een Nederlandstalige bewerking van Spielberger State-Trait Anxiety Inventory STAI-Y. Harcourt, Amsterdam.

Verwoerd, J., de Jong, P.J., Wessel, I., 2006. ACS: Dutch translation of the Attentional Control Scale, originally developed by Derryberry and Reed (2002). 